\title{
The effect of the combination of TGF- $\beta 1$ and BMP2 with high-density pellet cell culture during chondrogenic differentiation of pluripotent stem cells.
}

\author{
Michał S. Lach ${ }^{1,2,3}$, Wiktoria M. Suchorska ${ }^{1,2}$ \\ ${ }^{1}$ Radiobiology Lab, Greater Poland Cancer Centre, \\ ${ }^{2}$ Department of Electroradiology, Poznan University of Medical Sciences, \\ ${ }^{3}$ The Postgraduate School of Molecular Medicine, Medical University of Warsaw
}

\begin{abstract}
Introduction:

The osteoarthritis is a serious threat for well-developed and ageing countries. Present techniques of treatment of damaged cartilage are not sufficient. Hence, new strategies should be developed. One of the potential methods for the cartilage regeneration is use of pluripotent stem cells (PSC).
\end{abstract}

\section{Aim:}

The development of an efficient protocol of chondrogenic differentiation using PSC.

\section{Material and methods:}

The human embryonic stem cell line (BGo1V) was used in this study. The chondrogenic differentiation was performed using high-density pellet culture in the presence of TGF- $\beta 1(10 \mathrm{ng} / \mathrm{ml})$ and BMP2 (100 $\mathrm{ng} / \mathrm{ml}$ ). After 21 days, expression analysis of genes related to chondrogenesis was done. Additionally, the histological staining was performed to detect the deposition of proteoglycans and collagens in differentiated pellet culture.

Adres do korespondencji

Michał S. Lach

Radiobiology Lab,

Wielkopolskie Centrum Onkologii, ul. Garbary 15, 61-866 Poznań, Polska

Telefon. $+48618850-474$

e-mail: michal.lach@wco.pl 


\section{Results:}

Obtained pellets exhibited decreased expression of pluripotent markers. The upregulation of mesodermal marker and type II collagen was observed in differentiated pellets in the presence of applied growth factors. The histological analysis revealed mild deposition of proteoglycans and collagens.

\section{Conclusion:}

The presented approach allows to obtain chondrogenic pellets in their early stages of chondrogenesis.

Keywords: Regenerative medicine, Chondrogenic differentiation, Osteoarthritis, Pluripotent Stem Cells, Articular cartilage chondrocytes.

\section{Introduction}

The osteoarthritis (OA) in the near future will be the leading cause of disabilities, gaining the status of civilization disease [1]. The OA is related to the genetic predisposition, age, high body mass index, mechanical or idiopathic damages of the joint cartilage $[2,3]$. Due to limited vascularity of cartilage tissue, it has a lack of ability to regenerate. Moreover, the activation of chondrocytes allocated in a dense extracellular matrix (ECM), after the damage, enables their maturation and formation of painful osteophytes [4]. The lack of early symptoms is the main reason for diagnosis at advanced stages of the disease, leading to invasive therapeutic approaches such as total joint replacement, which affects patients' quality of life and put them at risk of severe side effects related to the revision surgeries $[5,6]$.

One of the potential solutions to that state is taking an advantage of the recent discoveries of tissue engineering [7,8]. The application of mesenchymal stromal cells (MSC) is studied very broadly since chondrocytes are originating from the mesoderm germ layer. However, MSC are usefull mostly in young patients, where their efficiency and differentiation potential is high [9]. Moreover, the source of MSC has a huge role in cartilage formation. It was established, that besides the high amount of MSC derived from fat tissue, their chondrogenic differentiation is less effective than MSC isolated from bone marrow, where their amount is relatively low [10].

The other interesting population with high potential for regenerative medicine purposes are pluripotent stem cells (PSC) [11]. Those populations could be divided into human embryonic stem cells (hESC) or induced pluripotent stem cells (iPSC). Due to ability to unlimited cell division and self-renewal, it could be an infinite source of cells for tissue engineering. However, the use of hESC arise some ethical issues due to their origin. IPSC overcome those doubts, but their long term usage consequences are still poorly described due to unknown genetic stability or tumorigenic potential by the usage of oncogenic factors during the reprogramming process. The use of iPS in regenerative medicine needs thorough research regarding their safety[12-14]. The common problem associated with the use of PSC is the lack of well-standardized protocols of differentiation that would allow obtaining a homogenous population, without the risk of developing a teratoma due to PSC remnants [15]. Besides those facts, application of PSC cells in regenerative medicine has more advantages than any other known cell populations.

For cartilage regeneration, a variety of approaches are used. One of them is based on intermediate step using embryoid body (EB) formation, which uses their natural ability of to form the cells of three germ layer or direct one by adding the scheduled combination of growth factors responsible for at first mesoderm formation and then chondrogenic differentiation [16-18]. However, EB forms a heterogeneous population of cells, which could affect the reproducibility of the differentiation approach [19,20]. On the other hand, the use of many growth factors could significantly increase the costs of the protocol $[16,21]$. Among those protocols, the most common growth factors used to form chondrocytes are members of TGF- $\beta$ (Transforming Growth Factor $\beta$ ) and BMP (Bone Morphogenic Protein) protein family, which were estimated to have a crucial role in the formation of limbs and were used with success in MSC differentiation high-density spheres [16,22]. Thus, we decided to create a protocol without EB formation step with minimal usage of growth factors to obtain a homogenous chondrogenic population of cells.with minimal usage of growth factors to obtain a homogenous 
chondrogenic population of cells.

\section{Aim}

To generate efficient protocol of chondrogenic differentiation from pluripotent stem cells using highdensity mass culture in combination with TGF- $\beta$ /BMP members' family.

\section{Materials and methods}

\section{- The PSC cell culture and chondrogenic differentiation}

The human embryonic stem cell line BGo1V (ATCC, VA, USA) were cultured as previously described [23]. After the depletion of feeder-cells for 3 passages, $1.5 \times 10^{5}$ PSC cells were suspended in a chondrogenic medium (ChM) and centrifuged for 5 minutes at $300 \mathrm{x}$. The ChM composition was previously established with minor modification [24]. Briefly, the ChM instead of $5 \%$ of Knock-out Serum Replacement (KSR, Thermo Fisher Scientific, USA) contained 1\%. Moreover, ChM was supplemented with TGF- $\beta 1$ (10 ng/ml) and BMP2 $(100 \mathrm{ng} / \mathrm{ml}$ ) (both provided by Immunotools $\mathrm{GmbH}$, Germany). The medium was changed every second day for 21 days with fresh supplementation of growth factors. As a control, BGo1V cells cultured in ChM without growth factors (GF) was used. The following variants were established: ChM - cells cultured in only ChM; $\mathrm{ChM}+\mathrm{GF}$ - cells cultured in ChM supplemented with growth factors.

\section{- Isolation of RNA and RT-qPCR analysis}

After 21 days of differentiation, the RNA was isolated from 6 pellets per replicate as previously described [24]. The cDNA synthesis and RT-qPCR analysis were performed as previously described [23,24]. The relative mRNA expression was first normalized to reference gene Glyceraldehyde 3-phosphate dehydrogenase (GAPDH) and then to controls: BGo1V cells or adult chondrocytes cell line HC-402-05a (Cells Applications Inc. CA, USA). The list of primers used in this study is enlisted in Table 1.

Table 1. The list of primers of genes used in that study.

\begin{tabular}{|c|c|c|c|}
\hline Target mRNA & Forward Sequence & Reverse Sequence & Probe no. \\
\hline ACAN & cgtgaatcagaatcaactgctg & Gtgtcectctgtctcettgc & 31 \\
\hline BRACHYURY & gatgatcgtgaccaagaacg & cttccagcggtggttgtc & 18 \\
\hline COL2A1 & ttctggagaccaaggtgctt & ttccattagcaccatctttgc & 67 \\
\hline COL1OA1 & caggccetaaaggtgagaca & caggggaaccectttcac & 45 \\
\hline NANOG & atgcctcacacggagactgt & aagtgggttgtttgcctttg & 31 \\
\hline SOX9 & ctcgccacactcctcctc & cgcttcaggtcagccttg & 77 \\
\hline
\end{tabular}

$A C A N$ - aggrecan; BRACHYURY - T-Box Transcription Factor T; COL2A1 - Collagen type 2 alpha 1 chain; COL1OA1 Collagen type 10 alpha 1 chain; SOX9 - SRY (sex-determining region Y)-box 9;

\section{- Immunohistochemical stainings}

After 21 days of culture, pellets were washed using phosphate-buffered saline (PBS, Biowest, France) and then rinsed in ready-to-use buffered formalin (POCH, Poland). After fixation, pellets were embedded in wax. Stainings were performed as previously described with minor modification [24]. Deparaffinized slices were stained for presence of type II collagen (dilution 1:300; ab34712, Abcam, UK) For the proteoglycans and other fibrils structures the trichrome Masson, Verhoeff - van Gieson, alcian blue, safranin-O, toluidine blue stainings were performed according to manufacturer's instruction (all chemicals was obtained from Sigma-Aldrich, MO, USA). The pictures of stained pellets were taken using Opta-Tech MW-10o inverted microscope and documented using Opta-View software (Opta-Tech, Poland). 


\section{- Statistical analysis}

The presented experiments were repeated at least three times. The statistical significance was calculated using Graph Pad Prism 6 (Graph Pad Software, CA, USA) using one-way ANOVA. Significant differences for $\mathrm{p}<0.05$ were acknowledged.

\section{Results}

\section{- The gene expression analysis of differentiated BGo1V cells}

After 21 days of differentiation of BGo1V cells in high-density culture, the consistent spheres were formed (Figure 1A andB). The gene expression analysis of the pluripotent marker, NANOG, was decreased in differentiated cells in comparison to control (Figure 2A).
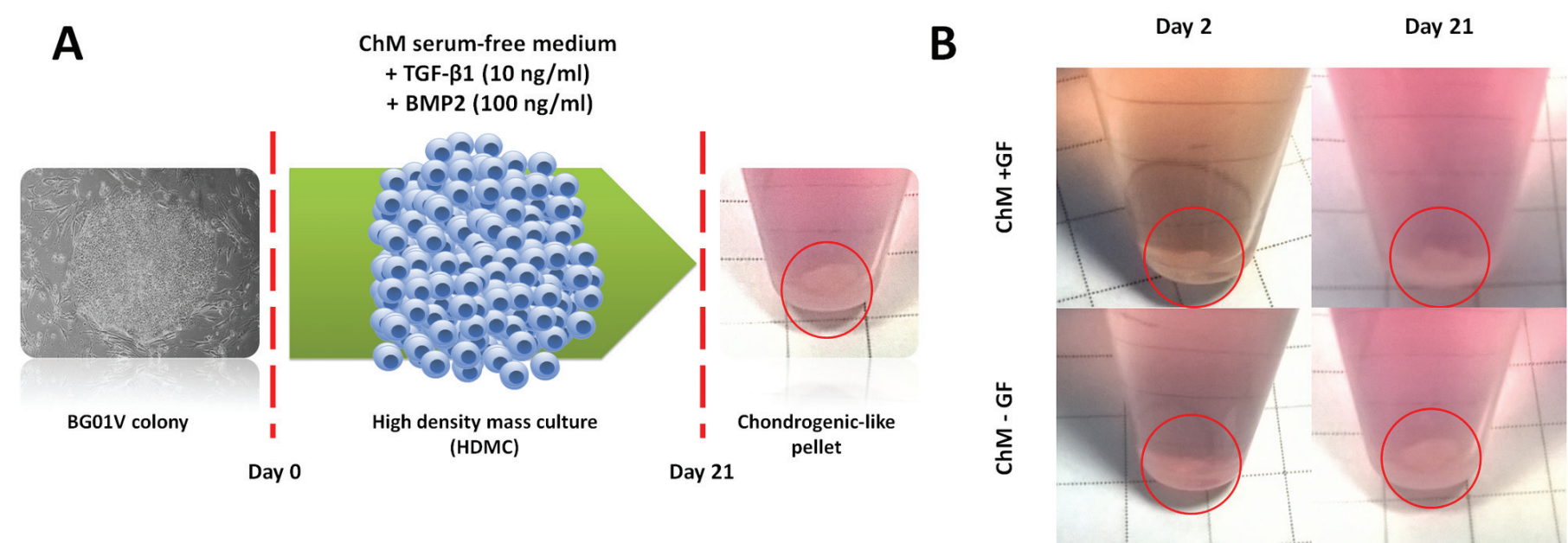

Figure 1. The scheme of the experiment (A) and representative picture of growing spheres during the differentiation process (B). BGo1V cells were cultured for 21 days in high-density culture in the serum-free chondrogenic medium (ChM) in the presence of TGF- $\beta 1$ and BMP-2, as a result, the formation of the consistent sphere was observed.

Among studied variants, the expression was slightly higher in pellets exposed to combined growth factors. In comparison with control cells BGo1V, the expression of BRACHURY was highly upregulated in differentiated ChM+GF pellets, even higher than in the ChM variant (Figure 2B). The adverse tendency was observed in chondrocytes hypertrophy marker COL1OA1 (Figure 2C). The lowest expression was notified in TGF- $\beta 1$ and $\mathrm{BMP} 2$ treated pellets in comparison with untreated spheres and control adult chondrocytes cell line HC-402-05a. Unfortunately, a similar observation was notified during SOX9 expression, one of the chondrocytes specific transcription factors, where the lowest expression was observed in ChM+GF variant (Figure 2D). However, chondrogenic medium alone and combined with TGF- $\beta 1$ and BMP2 caused upregulation of COL2A1, the main component of hyaline cartilage, in cultured spheres in comparison with control cell line (Figure 2E). However, its expression was lower in ChM+GF variant in comparison to pellets differentiated in ChM. The ACAN expression, one of the components of cartilage proteoglycans, was significantly lower in differentiated pellets in comparison with control (Figure 2F). Between the ChM and $\mathrm{ChM}+\mathrm{GF}$ spheres, there was a lack of differences in $A C A N$ expression. These results suggest obtaining of not fully differentiated chondrogenic-like cells exhibiting early chondrogenic population due to high expression of BRACHYURY but also presented specific markers for chondrocytes like SOX9 and COL2A1. 

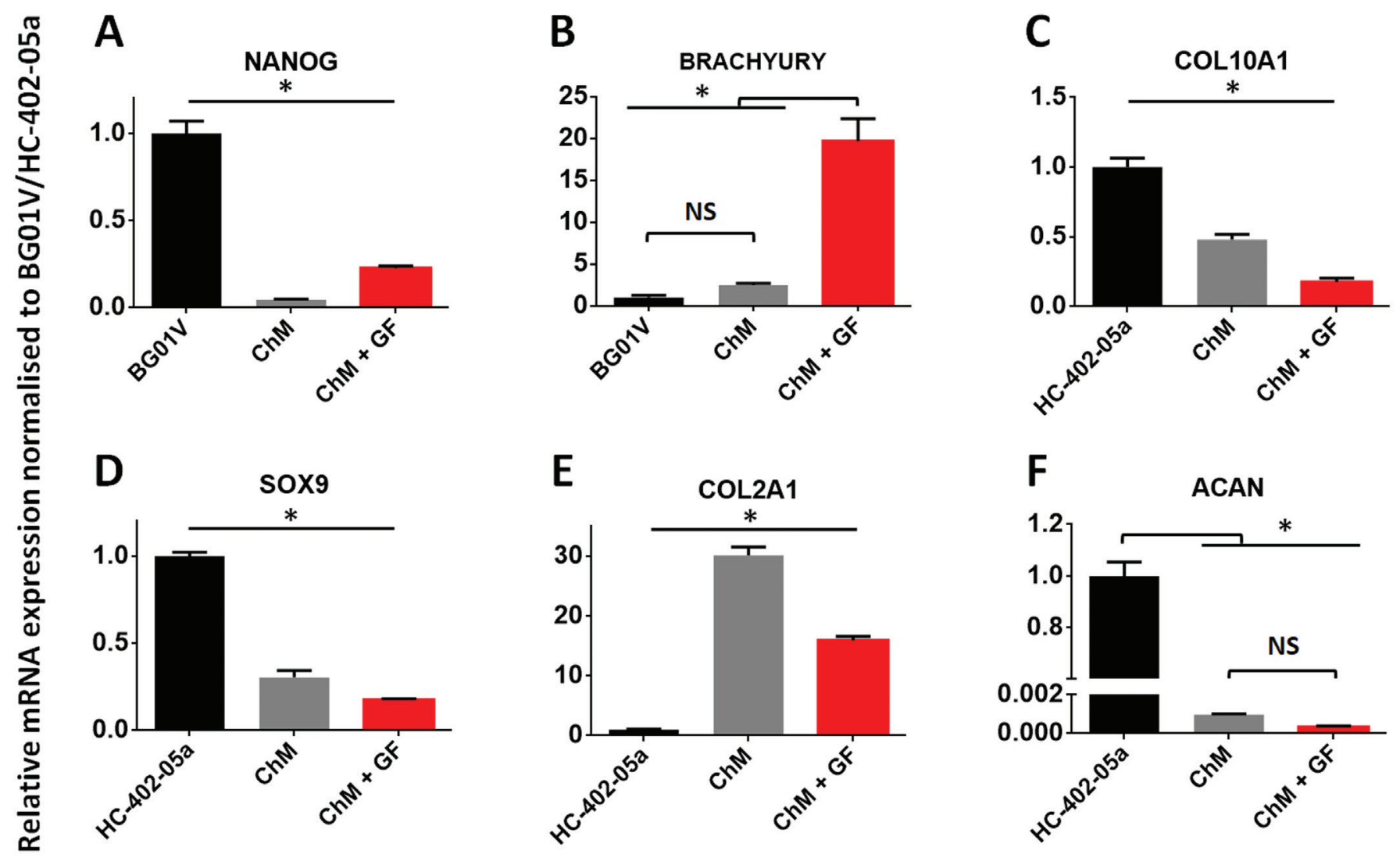

Figure 2. The characterization of genes related to chondrogenesis of studied spheres after the proposed chondrogenic differentiation approach. The marker of pluripotency $N A N O G$ (A); mesodermal lineage - BRACHURY (B); and chondrocytes - COL1OA1 (C), SOX9 (D), COL2A1 (E) and ACAN (F); were tested. The error bars represent SD. The statistical analysis was performed using one-way ANOVA with Tukey's post-hoc multi comparison test (* - p<0.05). ChM- Chondrogenic medium; ChM+GF - Chondrogenic medium combined with growth factors.

\section{The histological analysis of obtained pellets}

The obtained spheres as differentiated in presence of ChM medium alone and combined with TGF- $\beta 1$ and BMP2 undergo histological analysis for the presence of deposition of extracellular matrix (ECM) mostly proteoglycans and collagens (Figure 3). The intensity of Alcian blue, marker of proteoglycans, revealed the slightly higher intensity of their deposition in ChM+GF spheres. Similarly, type II collagen, a marker of hyaline cartilage, was more intensified in these spheres. The more reddish elements, representing collagen deposition, were observed in the Verhoeff-van Gieson stainings of pellets treated with TGF- $\beta 1$ and BMP2 than in those cultured in $\mathrm{ChM}$ alone, where yellowish structures representing cytoplasm or other non-cartilage related structures were detected. Masson trichrome staining, where blue structures are the indicator of collagens, revealed more intense blue elements in the ChM+GF variant in comparison with ChM. The gold standard staining of proteoglycans deposition in cartilaginous tissue - toluidine blue and safranin-O - also indicated the more intensified color in the pellets treated with TGF- $\beta 1$ and BMP2 than cultured in ChM alone. Moreover, the overlook onto histological morphology using HE staining of obtained spheres revealed that $\mathrm{ChM}+\mathrm{GF}$ variant consisted of more similar, homogenous cells than pellets differentiated in ChM alone. In general, these data support the derivation of chondrogenic-like spheres at the early stages of chondrogenesis. 


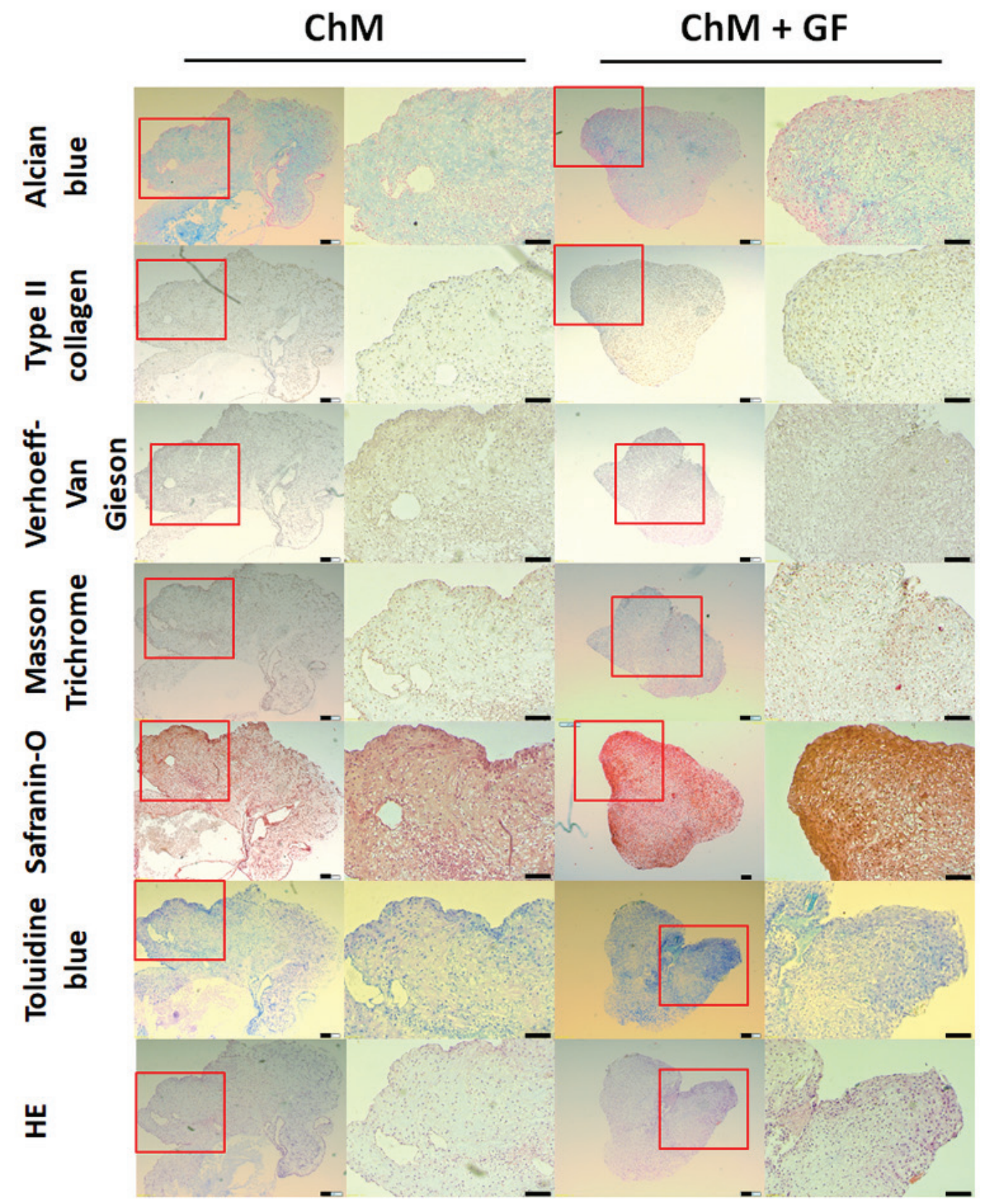

Figure 3. The immunohistochemical stainings of obtained spheres after 21 of chondrogenic differentiation. As control spheres cultured in ChM without GF was used. The dark scale bars represent $100 \mu \mathrm{m}$.

\section{Discussion}

In this study, we aimed to develop a simple protocol for chondrogenic differentiation from pluripotent stem cells with minimal supplementation of growth factors and culture system based on chondrocytes biology. Thus, we used TGF- $\beta 1$ and BMP2, which are known as chondroinductive growth factors commonly used in mesenchymal stromal cells chondrogenic differentiation [25-27]. Their combination is known for enhancing the production of ECM and the expression of markers specific for hyaline chondrocytes such as type II collagen [28]. In our study, we used a serum-free approach for chondrogenic differentiation. The use of fetal bovine serum (FBS) in cell culture arise some ethical issues and limits the application of these cells for clinic due to the variability of batches or risk of transferring animal-related diseases [29,30]. Moreover, it was shown that supplementation of FBS in chondrogenic culture is a negative factor, responsible for 
decreased production of ECM by differentiated MSC. One of the causes was related to the suppression of the effect of TGF- $\beta 1$ by its presence in the cell culture medium [31-33]but to date the standard culture model for these explants has required the addition of fetal bovine serum to the media. Numerous investigators have succeeded in culturing chondrocytes and embryonic cells in serum-free conditions but there have been no studies focused on achieving a defined, serum-free media for culturing periosteal explants. The purpose of the present investigation was to determine if whole periosteal explants can be grown and produce cartilage in serum-free conditions, and to define the minimum media supplements that would be conducive to chondrogenesis. 321 periosteal explants were obtained from the medial proximal tibiae of 31 two monthold NZ white rabbits and cultured using a published agarose suspension organ culture model and DMEM for six weeks. The explants were cultured with and without fetal bovine serum or bovine serum albumin and exposed to transforming growth factor beta alone, a combination of growth factors we call ChondroMix (10 $\mathrm{ng} / \mathrm{ml}$ transforming growth factor beta, $50 \mathrm{ng} / \mathrm{ml}$ basic fibroblast growth factor, and $5 \mu \mathrm{g} / \mathrm{ml}$ growth hormone. For the clinical use of PSC cells, there is a necessity to deplete feeder-cells for similar reasons as animalderived serum. The ability of formation and adaptation of PSC cells to the serum- and feeder-free increase their translational potential [34]. However, in our protocol, we used feeder-dependent cell culture of human embryonic stem cells. To eradicate their presence we passaged them a few times, but this is leading to their spontaneous differentiation. In a few studies, such an approach is used to produce a colony or in case of usage EB cell outgrowth, which enables to obtain the MSC-like cells population without additional growth factors [17,35]we assessed the in vitro chondrogenic potential of the pluripotent population versus an iPSC-derived mesenchymal-like progenitor population. We found the direct plating of undifferentiated iPSCs into highdensity micromass cultures in the presence of BMP-2 promoted chondrogenic differentiation, however these conditions resulted in a mixed population of cells resembling the phenotype of articular cartilage, transient cartilage, and fibrocartilage. The progenitor cells derived from human iPSCs exhibited immunophenotypic features of mesenchymal stem cells (MSCs. In our protocol, we applied three dimensional (3D) culture system was to provide the imitation of microenvironment close to chondrogenesis (mesenchymal condensation - a crucial process during limb formation) and provide scaffoldless construct for fulfilling cartilage defect [36$38]$ transforming growth factor $\beta 1$ (TGF- $\beta 1$. Another advantage of using the $3 \mathrm{D}$ environment is maintaining a stable phenotype of differentiated chondrocytes [29,38,39]. It was shown already that one of the causes of the autologous chondrocytes implantation (ACI) failure is related to in vitro expansion of chondrocytes, where dedifferentiation process occurs leading to the formation of fibrocartilage and hypertrophic chondrocytes representing adverse biomechanical properties than naive hyaline cartilage [40-42].

In our study, the derived ChM+GF pellets indicated the presence of higher expression of NANOG than in cells treated only with ChM. This is one of the cons of using that protocol for clinics in current form, due to the possible teratoma formation [43]. NANOG presence could be related to the short time of differentiation and use of TGF- $\beta 1$, which is known factor for maintaining pluripotency state [44]. In our presented protocol we were able to obtain cells at the early stages of chondrogenesis. . One of the supporting data is the enhanced expression of BRACHYURY in differentiated pellets. It was assessed that this transcription factor is highly connected with chondrogenic differentiation in BMP2 dependent manner and activation of FGF-signalling pathway in murine MSC cells [45]. Moreover, the hypothesis of the early chondrogenic population is supported by the low expression of COL10A1. Its upregulation is one of the markers of maturation, dedifferentiation and hypertrophic of chondrocytes [46,47]. Besides those revelations in our spheres treated with GFs, we observed lower mRNA expression of COL2A1 in comparison to ChM treated cells. This could be related to ingredients of the chondrogenic medium itself - L-ascorbic acid and dexamethasone, which are known factors enhancing the expression of SOX9 and COL2A1 [48-51]. Contrary, the histological analysis revealed increased deposition of type II collagen in GF treated spheres. This protein is highly expressed in hyaline cartilage, where is responsible for its elasticity and ability to trap the proteoglycans, forming the complex structure resistant to bear weight and enabling the frictionless and painless movements of the joints. In the case of proteoglycans, in our protocol, the ACAN expression was low in comparison with adult articular chondrocytes, but the histological staining detected mild intensity of deposited proteoglycans in our differentiated cells. All these findings taken together support the obtaining of prochondrogenic state of our pellets. However, for their further maturation, the extended time of differentiation and microenvironmental stimulation is necessary. Recently reported in vivo studies of chondrogenic PSC differentiation by several 
independent groups have shown that implantation of prochondrogenic pellets (around 30 days of $3 \mathrm{D}$ culture) with low-deposited proteoglycans enabled formation hyaline cartilage in the damaged site [36,52-54]. One of the studies suggested that early stage for implantation could improve integration with donor tissue because in the prolonged cultured chondrogenic pellets formation of lubricious phase on their surface is observed $[36,55]$.

\section{Conclusions}

The high-density culture chondrogenic differentiation of PSC in the presence of TGF- $\beta 1$ and BMP2 enable to form the chondrogenic-like spheres at the early stage of differentiation. Prolonged culture of spheres and in vivo models should be used for further observation of their maturation related to joint microenvironmental factors and confirmation of their safety due to PSC remnants.

\section{Funding}

This research project was funded by the National Science Centre project No. 2012/07/E/NZ3/01819.

\section{Conflict of interest}

The authors declare no conflict of interest.

\section{References}

[1] E. Stanisławska-Biernat, Social and economic aspects of osteoarthritis, Polish Arch. Intern. Med. 118 (2008) 50-53.

[2] D. Umlauf, S. Frank, T. Pap, J. Bertrand, Cartilage biology, pathology, and repair., Cell. Mol. Life Sci. 67 (2010) 4197-4211.

[3] M. Richter, T. Trzeciak, J.D. Rybka, W. Suchorska, E. Augustyniak, M. Lach, M. Kaczmarek, J. Kaczmarczyk, Correlations between serum adipocytokine concentrations, disease stage, radiological status and total body fat content in the patients with primary knee osteoarthritis, Int. Orthop. 41 (2017) 983-989.

[4] R.L. Taruc-Uy, S.A. Lynch, Diagnosis and Treatment of Osteoarthritis, Prim. Care - Clin. Off. Pract. 40 (2013) 821-836.

[5] B. Kurcz, J. Lyons, Z. Sayeed, A.A. Anoushiravani, R. Iorio, Osteolysis as it Pertains to Total Hip Arthroplasty, Orthop. Clin. North Am. 49 (2018) 419-435.

[6] X. a Li, S. Iyer, M.B. Cross, M.P. Figgie, Total joint replacement in adolescents: literature review and case examples., Curr. Opin. Pediatr. 24 (2012) 57-63.

[7] N. Mahmoudifar, P.M. Doran, Chondrogenesis and cartilage tissue engineering: the longer road to technology development, Trends Biotechnol. 30 (2012) 166-176.

[8] M. Lach, T. Trzeciak, M. Richter, J. Pawlicz, W.M. Suchorska, Directed differentiation of induced pluripotent stem cells into chondrogenic lineages for articular cartilage treatment, J. Tissue Eng. 5 (2014) 204173141455270.

[9] M. Kanawa, A. Igarashi, V.S. Ronald, Y. Higashi, H. Kurihara, M. Sugiyama, T. Saskianti, H. Pan, Y. Kato, Age-dependent decrease in the chondrogenic potential of human bone marrow mesenchymal stromal cells expanded with fibroblast growth factor-2, Cytotherapy. 15 (2013) 1062-1072.

[10] S. Mohamed-Ahmed, I. Fristad, S.A. Lie, S. Suliman, K. Mustafa, H. Vindenes, S.B. Idris, Adiposederived and bone marrow mesenchymal stem cells: a donor-matched comparison, Stem Cell Res. Ther. 9 (2018) 168.

[11] O.S. Beane, E.M. Darling, Isolation, characterization, and differentiation of stem cells for cartilage regeneration, Ann. Biomed. Eng. 40 (2012) 2079-2097.

[12] J. Bilic, J.C. Izpisua Belmonte, Concise review: Induced pluripotent stem cells versus embryonic stem cells: Close enough or yet too far apart?, Stem Cells. 30 (2012) 33-41. 
[13] C. Eguizabal, B. Aran, S.M. Chuva de Sousa Lopes, M. Geens, B. Heindryckx, S. Panula, M. Popovic, R. Vassena, A. Veiga, Two decades of embryonic stem cells: a historical overview, Hum. Reprod. Open. 2019 (2019) hoyo24.

[14] S.A. Lietman, Induced pluripotent stem cells in cartilage repair, World J. Orthop. 7 (2016) 149-155.

[15] M.K. Carpenter, J. Frey-Vasconcells, M.S. Rao, Developing safe therapies from human pluripotent stem cells., Nat. Biotechnol. 27 (2009) 606-613.

[16] E. Augustyniak, T. Trzeciak, M. Richter, J. Kaczmarczyk, W. Suchorska, The role of growth factors in stem cell-directed chondrogenesis: a real hope for damaged cartilage regeneration, Int. Orthop. 39 (2015) 995-1003.

[17] H. Nejadnik, S. Diecke, O.D. Lenkov, F. Chapelin, J. Donig, X. Tong, N. Derugin, R.C.F.F. Chan, A. Gaur, F. Yang, J.C. Wu, H.E. Daldrup-Link, Improved Approach for Chondrogenic Differentiation of Human Induced Pluripotent Stem Cells, Stem Cell Rev. Reports. 11 (2015) 242-253.

[18] R.A. Oldershaw, M.A. Baxter, E.T. Lowe, N. Bates, L.M. Grady, F. Soncin, D.R. Brison, T.E. Hardingham, S.J. Kimber, Directed differentiation of human embryonic stem cells toward chondrocytes, Nat. Biotechnol. 28 (2010) 1187-1194.

[19] T. Nakagawa, S.Y. Lee, a H. Reddi, Induction of chondrogenesis from human embryonic stem cells without embryoid body formation by bone morphogenetic protein 7 and transforming growth factor beta1., Arthritis Rheum. 60 (2009) 3686-3692.

[20] Y.Y. Choi, B.G. Chung, D.H. Lee, A. Khademhosseini, J.-H. Kim, S.-H. Lee, Controlled-size embryoid body formation in concave microwell arrays., Biomaterials. 31 (2010) 4296-4303.

[21] W.M. Suchorska, E. Augustyniak, M. Richter, T. Trzeciak, Comparison of Four Protocols to Generate Chondrocyte-Like Cells from Human Induced Pluripotent Stem Cells (hiPSCs), Stem Cell Rev. Reports. 13 (2017) 299-308.

[22] B. Keller, T. Yang, Y. Chen, E. Munivez, T. Bertin, B. Zabel, B. Lee, Interaction of TGF $\beta$ and BMP signaling pathways during chondrogenesis., PLoS One. 6 (2011) e16421.

[23] Authors 2018.

[24] Authors 2019.

[25] W.S. Toh, H. Liu, B.C. Heng, A.J. Rufaihah, C.P. Ye, T. Cao, Combined effects of TGFbeta1 and BMP2 in serum-free chondrogenic differentiation of mesenchymal stem cells induced hyaline-like cartilage formation., Growth Factors. 23 (2005) 313-321.

[26] L. Danišovič, I. Varga, Š. Polák, Growth factors and chondrogenic differentiation of mesenchymal stem cells, Tissue Cell. 44 (2012) 69-73.

[27] W.S. Toh, E.H. Lee, T. Cao, Potential of human embryonic stem cells in cartilage tissue engineering and regenerative medicine., Stem Cell Rev. 7 (2011) 544-559.

[28] M.K. Murphy, D.J. Huey, J.C. Hu, K.A. Athanasiou, TGF- $\beta 1$, GDF-5, and BMP-2 Stimulation Induces Chondrogenesis in Expanded Human Articular Chondrocytes and Marrow-Derived Stromal Cells, Stem Cells. 33 (2015) 762-773.

[29] S.T.B. Ho, Z. Yang, H.P.J. Hui, K.W.S. Oh, B.H.A. Choo, E.H. Lee, A serum free approach towards the conservation of chondrogenic phenotype during in vitro cell expansion, Growth Factors. 27 (2009) 321333.

[30] C.E.A. Jochems, J.B.F. van der Valk, F.R. Stafleu, V. Baumans, The use of fetal bovine serum: ethical or scientific problem?, Altern. Lab. Anim. 30 (2002) 219-227.

[31] B. Bilgen, E. Orsini, R.K. Aaron, D.M. Ciombor, FBS suppresses TGF- $\beta 1$-induced chondrogenesis in synoviocyte pellet cultures while dexamethasone and dynamic stimuli are beneficial, J. Tissue Eng. Regen. Med. 1 (2007) 436-442.

[32] J.S. Fitzsimmons, A. Sanyal, C. Gonzalez, T. Fukumoto, V.R. Clemens, S.W. O’Driscoll, G.G. Reinholz, Serum-free media for periosteal chondrogenesis in vitro, J. Orthop. Res. 22 (2004) 716-725.

[33] K. Endo, N. Fujita, T. Nakagawa, R. Nishimura, Effect of fibroblast growth factor-2 and serum on canine mesenchymal stem cell chondrogenesis, Tissue Eng. Part A. 25 (2018) 901-910.

[34] M.S. Lach, J.P. Wroblewska, E. Augustyniak, K. Kulcenty, W.M. Suchorska, A feeder- and xeno-free human induced pluripotent stem cell line obtained from primary human dermal fibroblasts with epigenetic repression of reprogramming factors expression: GPCCioo1-A, Stem Cell Res. 20 (2017) 34- 
37.

[35] R.M. Guzzo, J. Gibson, R.-H. Xu, F.Y. Lee, H. Drissi, Efficient differentiation of human iPSC-derived mesenchymal stem cells to chondroprogenitor cells., J. Cell. Biochem. 114 (2013) 480-490.

[36] A. Yamashita, M. Morioka, Y. Yahara, M. Okada, T. Kobayashi, S. Kuriyama, S. Matsuda, N. Tsumaki, Generation of scaffoldless hyaline cartilaginous tissue from human iPSCs, Stem Cell Reports. 4 (2015) 404-418.

[37] M.B. Goldring, Chondrogenesis, chondrocyte differentiation, and articular cartilage metabolism in health and osteoarthritis., Ther. Adv. Musculoskelet. Dis. 4 (2012) 269-285.

[38] M. Centola, B. Tonnarelli, S. Schären, N. Glaser, A. Barbero, I. Martin, Priming 3D Cultures of Human Mesenchymal Stromal Cells Toward Cartilage Formation Via Developmental Pathways, Stem Cells Dev. 22 (2013) 2849-2858.

[39] N. Ahmed, J. Iu, C.E. Brown, D.W. Taylor, R.A. Kandel, Serum- and Growth-Factor-Free ThreeDimensional Culture System Supports Cartilage Tissue Formation by Promoting Collagen Synthesis via Sox9- Col2a1 Interaction, Tissue Eng. Part A. 20 (2014) 2224-2233.

[40] J.-D. Wei, H. Tseng, E.T.-H. Chen, C.-H. Hung, Y.-C. Liang, M.-T. Sheu, C.-H. Chen, Characterizations of Chondrocyte Attachment and Proliferation on Electrospun Biodegradable Scaffolds of PLLA and PBSA for Use in Cartilage Tissue Engineering, J. Biomater. Appl. . 26 (2012) 963-985.

[41] M. Falah, G. Nierenberg, M. Soudry, M. Hayden, G. Volpin, Treatment of articular cartilage lesions of the knee., Int. Orthop. 34 (2010) 621-630.

[42] J.-L. Chen, L. Duan, W. Zhu, J. Xiong, D. Wang, Extracellular matrix production in vitro in cartilage tissue engineering., J. Transl. Med. 12 (2014) 88.

[43] N. Desai, P. Rambhia, A. Gishto, Human embryonic stem cell cultivation: Historical perspective and evolution of xeno-free culture systems, Reprod. Biol. Endocrinol. 13 (2015) 9.

[44] S. Yamasaki, Y. Taguchi, A. Shimamoto, H. Mukasa, H. Tahara, T. Okamoto, Generation of Human Induced Pluripotent Stem (iPS) Cells in Serum- and Feeder-Free Defined Culture and TGF- $\beta 1$ Regulation of Pluripotency, PLoS One. 9 (2014) e87151.

[45] A. Hoffmann, S. Czichos, C. Kaps, D. Bächner, H. Mayer, B.G. Kurkalli, Y. Zilberman, G. Turgeman, G. Pelled, G. Gross, D. Gazit, The T-box transcription factor Brachyury mediates cartilage development in mesenchymal stem cell line C3H10T1/2., J. Cell Sci. 115 (2002) 769-781.

[46] J.-Y. Ko, K.-I. Kim, S. Park, G.-I. Im, In vitro chondrogenesis and in vivo repair of osteochondral defect with human induced pluripotent stem cells, Biomaterials. 35 (2014) 3571-3581.

[47] J.A. Martin, J.A. Buckwalter, The role of chondrocyte senescence in the pathogenesis of osteoarthritis and in limiting cartilage repair., J. Bone Joint Surg. Am. 85-A Suppl (2003) 106-110.

[48] A. Derfoul, G.L. Perkins, D.J. Hall, R.S. Tuan, Glucocorticoids promote chondrogenic differentiation of adult human mesenchymal stem cells by enhancing expression of cartilage extracellular matrix genes., Stem Cells. 24 (2006) 1487-1495.

[49] I. Sekiya, P. Koopman, K. Tsuji, S. Mertin, V. Harley, Y. Yamada, K. Shinomiya, A. Nifuji, M. Noda, Dexamethasone enhances SOX9 expression in chondrocytes, J. Endocrinol. 169 (2001) 573-579.

[50] Y. Sato, H. Mera, D. Takahashi, T. Majima, N. Iwasaki, S. Wakitani, M. Takagi, Synergistic effect of ascorbic acid and collagen addition on the increase in type 2 collagen accumulation in cartilage-like MSC sheet, Cytotechnology. 69 (2017) 405-416.

[51] A.G. Clark, A.L. Rohrbaugh, I. Otterness, V.B. Kraus, The effects of ascorbic acid on cartilage metabolism in guinea pig articular cartilage explants, Matrix Biol. 21 (2002) 175-184.

[52] A. Yamashita, Y. Tamamura, M. Morioka, P. Karagiannis, N. Shima, N. Tsumaki, Considerations in hiPSC-derived cartilage for articular cartilage repair, Inflamm. Regen. 38 (2018) 17.

[53] D. Yang, S. Chen, C. Gao, X. Liu, Y. Zhou, P. Liu, J. Cai. Chemically defined serum-free conditions for cartilage regeneration from human embryonic stem cells, Life Sci. 164 (2016) 9-14.

[54] Y. Nam, Y.A. Rim, S.M. Jung, J.H. Ju. Cord blood cell-derived iPSCs as a new candidate for chondrogenic differentiation and cartilage regeneration, Stem Cell Res. Ther. 8 (2017) 1-13.

[55] J. van de Breevaart Bravenboer, C.D. In der Maur, P.K. Bos, L. Feenstra, J.A.N. Verhaar, H. Weinans, et al. Improved cartilage integration and interfacial strength after enzymatic treatment in a cartilage transplantation model., Arthritis Res. Ther. 6 (2004) R469-R476. 